\title{
Reseña del libro: La vida inmortal de Henrietta Lacks
}

\author{
Autora: Rebecca Skloot
}

Ediciones Martínez Roca | Año 2010 | ISBN: 978-84-8460-993-3

DOI 10.46588/invurnus.v16i1.45

Recibido 22/11/2021

Aceptado 14/12/2021

Publicado 15/12/2021

Rebecca Skloot, la autora del libro "La vida inmortal de Henrietta Lacks" (título en inglés: "The immortal life of Henrietta Lacks"), se empeñó durante varios años, en recopilar toda la información disponible sobre la vida y el legado de Henrietta Lacks; alguna de primera mano, relatada por sus hijos y familiares cercanos, otra de artículos, documentos legales y el historial médico de Henrietta. Toda esta información, mantenida en la sombra por décadas, la plasmó en su libro, donde de manera relatada, nos transporta de los años 1950s a los 1990-2000s y de vuelta, en una serie de narraciones sobre la vida de Henrietta Lacks, el ámbito científico de aquella época y los retos y avances en el campo de la

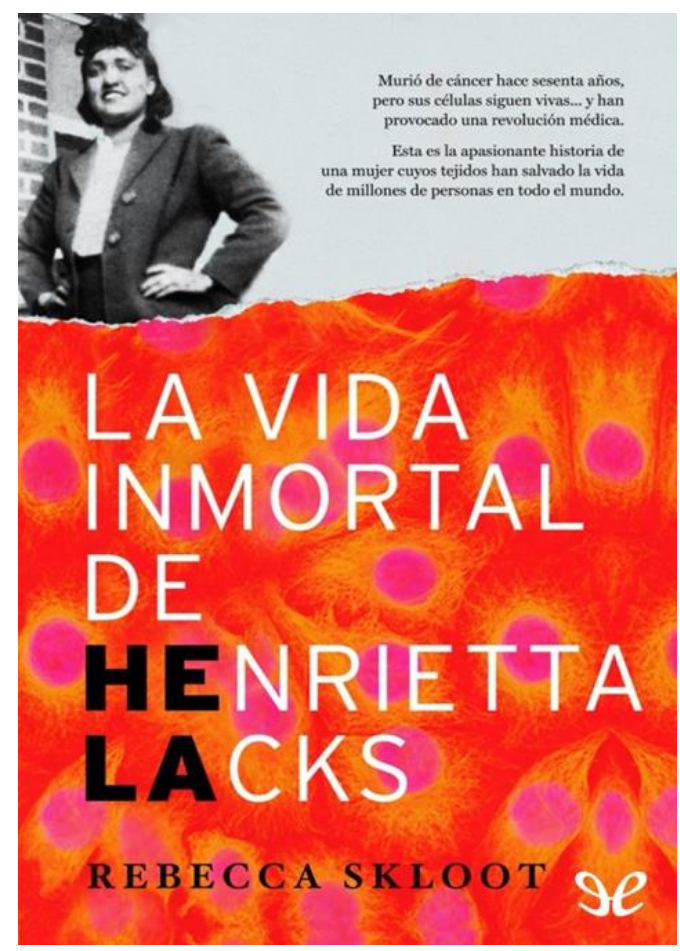
medicina de los años 1950s.

El libro comienza hablando de Henrietta, una joven afroamericana de 30 años, nacida en Roanoke, Virginia, madre de cuatro hijos, que en enero del año 1951 acude al hospital Johns Hopkins (en Baltimore, Estados Unidos) por un dolor abdominal bajo que la aqueja desde hace algún tiempo. El médico, después de realizar 
una serie de estudios, diagnostica a Henrietta con cáncer cervical maligno. La joven se somete a terapia con radio, muy común para tratar ese tipo de cáncer en aquella época. El día de la terapia, y sin consentimiento previo de la paciente, el médico decide tomar una pequeña muestra de tejido tumoral, antes de aplicar el radio. Esa muestra biológica es inmediatamente transportada a un laboratorio, en donde un grupo de investigadores, liderados por el Dr. Gey, están tratando desde hace tiempo cultivar células humanas fuera de un organismo vivo, hasta entonces, sin éxito. En los años 1950s aún no existía toda la tecnología, y particularmente el conocimiento para hacer esto posible.

Rebecca Skloot, la autora de este libro, rápidamente nos pone en el contexto de la investigación en el área médica de aquella época, en donde no se usaban las campanas de bioseguridad biológica, no existían técnicas estandarizadas de mantenimiento y criopreservación de células, ni tampoco se conocía qué nutrientes exactamente necesitaban las células para poder sobrevivir. Sin embargo, el equipo científico del Dr. Gey era uno de los pioneros en empezar a establecer estas condiciones. En un pequeño cuarto hermético, siguiendo los protocolos de esterilidad de la época, en manos de Mary (una de las asistentes del laboratorio del Dr. Gey), nace la línea celular HeLa. Las células toman su nombre de las dos primeras letras del nombre y apellido de la paciente (Henrietta Lacks), como otras numerosas muestras de tejido que pasaron por las manos de Mary. Mientras tanto, Henrietta se está recuperando de su primer tratamiento de radio en el hospital, ignorando totalmente que sus células estaban siendo estudiadas. Desafortunadamente, poco tiempo después Henrietta fallece, perdiendo la batalla contra el cáncer, sin jamás conocer el impacto que tendrán las células HeLa en la medicina moderna.

Como narra el libro, a diferencia del resto de las células aisladas de muestras de tejido en el laboratorio del Dr. Gey, las células HeLa empiezan a multiplicarse rápido y de pronto hay tantas de ellas que las comienzan a regalar a otros investigadores. Años después, las células HeLa no solo ayudaron a desarrollar nuevas técnicas y recetas para medios de cultivo celular, sino fueron clave en el desarrollo de la vacuna contra la polio, avances en quimioterapias, clonación, cartografía genética y fertilización in vitro. Incluso, las células de Henrietta fueron al espacio para ser parte de experimentos que nos ayudaron a entender qué les sucede a las células humanas en gravedad cero.

A Henrietta le tocó vivir en una época, en la cual los ciudadanos de descendencia afroamericana en Estados Unidos no tenían los mismos derechos que los ciudadanos caucásicos. "La historia de Henrietta Lacks y las células HeLa plantea importantes cuestiones sobre ciencia, ética, raza y clase”, dice la autora de este libro. "Estoy segura de que (a Henrietta) le asombraría saber - como a casi todos nosotros - que ahora hay más de 
miles de millones de células suyas creciendo en los laboratorios de los que jamás hubo en su cuerpo". Este libro es una lectura ampliamente recomendada no solo para profesionistas del campo de ciencias de la salud, sino también para el público en general que disfruta leer libros históricos sobre personas que han trascendido. Nos hace reflexionar sobre la importancia de la ética en la ciencia y también apreciar los avances que se han tenido en el campo de la medicina y las ciencias de la salud en menos de un siglo.

- Yulia Lipovka, Ph.D.

Universidad de Sonora 